\title{
Difficulties in Leading Change in Non-profit Organizations
}

\author{
Zhang Pengpeng \\ Department of Social Science, Chinese University of Hong Kong, Hong Kong
}

Email address:

kuailezpp@163.com

\section{To cite this article:}

Zhang Pengpeng. Difficulties in Leading Change in Non-Profit Organizations. International and Public Affairs. Vol. 2, No. 1, 2018 , pp. $23-27$. doi: $10.11648 /$ j.ipa.20180201.13

Received: March 2, 2018; Accepted: April 8, 2018; Published: May 7, 2018

\begin{abstract}
As the development of society is continued and lays a great impact on society, nonprofit organizations are also under this influence and are prompted to change and grow vigorously. According to Henry Mintzberg, he believes that change is not single-factor directed. It is not a simple linear process. It is a complex process with intricate relations. Accordingly, change in organizations can be depicted as a system of moving cycles [1]. At present nonprofit organizations are facing a series of reforms which is an irresistible trend. However, the nonprofit organizations are surrounded by barriers which impede their development. This article will analyze the factors which hinder the advance of nonprofit organizations. Within organizations, internal reasons mainly include the restriction of ideas, institutional systems and inadequate resources. External reasons mainly include the restriction of system and government.
\end{abstract}

Keywords: Non-profit Organizations, Government, Management, Resources

\section{Introduction}

With the rapid economic and social development, the social problems have also become increasingly prominent since China entered the transition period. The government has adopted a series of measures to cultivate and foster non-profit organizations to alleviate such social pressures. Therefore, a burgeoning development of non-profit organization is a tendency in China. On the International Social Workers Day in 2014, Li Liguo, Minister of Civil Affairs, said that the number of private social service agencies in China has reached 2,400 [2]. However, non-profit organizations are facing difficulties in raising funds, attracting talents, and managing organizations. At present, social organizations have a strong dependence on government procurement of social services [3] Most of the existing non-profit organizations have a single operating model, relying excessively on the government, and having a low level of specialization. In addition, with the large number of social professionals are continuously departing from organizations, the long-term development of organizations is tough. In the face of fierce competition, how to dig out the reasons that impede the change of non-profit organizations has become the most important issue for a more efficient progress.

\section{Internal Factors}

The characteristics of the organization will restrain or enhance the autonomy of managers. The three factors that affect organizational change are conceptual barriers from organization and manager, the inadequacy of resources, and institutional imperfection. These factors will affect the managers' capability and freedom to carry out strategic changes.

\subsection{Conceptual Barriers}

\subsubsection{Organizational Inertia}

Organizational inertia is an attribute of an organization. It refers to an inclination of the organization to maintain the original thinking mode and the customary behavior mode. Especially when the original thinking mode and behavior mode have produced favorable results for the organization, the more successful cases bring about the greater inertia [4].

Organizational inertia greatly determines the mode of operation, direction and fate of non-profit organizations, hinders managers' freedom of choice within the organization, and reduces the flexibility of implementing changes in key areas [5]. Especially with the expansion of organization scale, the inertia will reduce the manager's freedom to change the organization, because these non-profit organizations have built their own management standardization and hierarchical 
structure. If this inertia continues to grow, managers would only increasingly recognize and vindicate these rules and structures long established by the organization rather than breaking them [6]. Therefore, when the actual performance is lower than the operating expectations, the greater the inertia constraint of the organization, the more likeness that the manager will lose opportunity and courage to break through, thus the degree of strategic change is weakened.

Therefore, when analyzing problems and making decisions, managers incline to consciously or unconsciously think along the past and habitual directions and paths, and then solve the problems in fixed mode. For example, when raising funding, most non-profit organizations rely on government grants rather than create more methods to get capital resources. With the implementation of the lump-sum grant in 2000, the share of government-funded funds in the income of NPOs decreased while the income from paid service increased [7]. But until now, the government funding still accounts for $71 \%$ of total revenue in nonprofit organizations. Many new ways of obtaining resource appear, but few organizations choose to go such novel ways. When nonprofit organizations rely on a single source for a long time, the organization tends to mimic the structure and behavior of the government who provides main sources. In other words, other means of getting funds, such as public donations or project fee income, all signal the organization's possible future transformation direction. These fixed patterns in nonprofit organizations are making organizational innovation face a great obstacle.

\subsubsection{Lack of Transformational Leadership}

Several studies show that leaders in the process of organizational change show a significant impact. It is generally accepted that leadership is the key factor in identifying opportunities and challenges and making the most effective transformation.

Transformational leadership emphasizes charisma and its impact on subordinates' feelings and values. Transformational leaders provide a clear expectation, which encourages followers to challenge the organization's original state through ethical behavior, equipping them the initiative to concern about and solve problems. Transformational leadership looks at the changes that organizations face, portrays a new vision for the organization, and empowers employees to break free and set their sights high.

Transformational leadership is based on a series of behavioral characteristics, such as the charm, the emotional appeal, the stimulation of the staff's intelligence and the caring for the subordinate. Firstly, transformational leadership emphasizes the building of cohesion within the team and encourages the sharing of ideas and the effective communication within the team. Transformational leaders encourage their employees to think divergently and creatively, and guide the ideological emancipation among employees to create a good innovation atmosphere for a team [8]. Secondly, leaders are very supportive on subordinates' self-learning and self-growth, in the process of establishing mutual trust among managers and employees.
However, in some non-profit organizations, senior managers are not such open-minded. What's worse, they are even afraid of any dissemination of ideas and sign of a new development. The for-profit organization emphasizes that leaders must have innovative entrepreneurial spirit, and the leadership style is relatively proactive. However, due to the nature of public welfare, non-profit organizations mainly organize projects not for making more money, leadership style tends to be passive [9]. They are limited by both external environment and inner passivism. If change means taking risks at the same time, they'd rather remain the current situation without taking a forward step. These managers see no threats or necessity to adventure their current positions.

\subsection{Organizational Resources}

\subsubsection{Capital Resources}

The non-profitability of social service organizations has determined that they have weaknesses in the construction of institutional infrastructure and integration of resources, thus they need relatively strong resources to support them [10]. Managers need to have adequate resources as a guarantee for implementing any strategy. The more abundance of the resources, the higher organizational autonomy [11]. Possessing more manageable resources gives managers more room to yield the greatest returns on investment, so managers have more opportunity for exploratory behavior [12]. Given more funds, nonprofit organizations can allocate more resources for new product designing to meet customer needs or implement regional sales to break through the limitations of regional development. Therefore, when the actual performance is lower than the operating expectations, the managers with higher resource operation rights will have greater space and autonomy in strategic planning, which will eventually strengthen the strategic transformation.

The capital resources of nonprofit organizations refer to the activities and funds owned by nonprofit organizations, which include both the cost of service activities provided by the organization and the expenses of supporting the daily works. However, judging from the reality, the supply of charity resources in China is far from meeting the growing public demand. This situation of supply shortage is mainly reflected in two aspects. Firstly, under the condition that the protection systems in many aspects are still not perfect, the people's public welfare needs are relatively high; secondly, the amount of rescue objects is huge, but the corresponding rescue ability is relatively weak. It can be said that for a long period of time, the supply of charity resources is still one of the difficulties that China faces [13].

First, the lack of funds has become a stumbling block to the development of charities in China. For the organization itself, the main reason for the serious lack of funding for activities lies in that the donation mechanism is not legitimate, reasonable and effective, blindly relying on the government's financial allocations which may be a single source of funding. In addition, the administrative orientation of fund-based public welfare organizations is also rather serious. Only those foundations with official backgrounds can obtain relevant government support 
and preferential policies [14]. Especially in economic downturn financial difficulties of the non-profit organizations may make them reel from the economic turmoil. The truth is, the under-funding of non-profit organizations is a fairly common issue. According to the survey conducted by a scholar, government subsidies accounted for more than half of the revenue sources of Chinese charity organizations. Contributions and operating income accounted for nearly one-third. Individual and corporate donations amounted to only one-tenth. Foreign donations were negligible, only $2 \%$ [15].

Second, non-profit organizations lack a sound and effective fundraising mechanism. At present, non-profit organizations are basically playing all kinds of roles in a body. There is no specialized division of labor. Non-profit organizations are not only the entity to raise funds, but also the entity to operate funds. This is not conducive for donors to make an effective monitoring of the use of donations, thus causing public suspicion of the credibility of non-profit organizations. Insofar as social donation is concerned, compared with foreign countries, the cultural foundation for welfare in China is still relatively unstable, and the social donation system has a far cry from other advanced systems [16]. Therefore, after the transformation of public welfare institutions, they will generally face the problem of insufficient funding sources. In addition, it also virtually aggravates the non-profit organization's own administrative expenses and the work load of the organization staffs, which inevitably impair the effectiveness and efficiency of the work.

\subsubsection{Human Resource}

An organization never be automatically appeared. It requires accumulation and utilization of resources [17]. These resources include supplies, energy, information and human. A large number of organizations doom to wither away due to the inaccessibility of the nourishment necessary for their survival under certain circumstances. The organization's power to handle a butcher's cleaver is closely linked to its sound ability to mobilize and utilize resources. When other conditions remain the same, the amount of resources an organization can obtain determine the organization's room to play.

As far as human resources are concerned, there are currently several weaknesses in the non-profit organizations. First, there is a lack of highly qualified personnel. In the modern society, the priority of interests is paid more and more attention. However, non-profit organizations emphasize unpaid volunteering, so few people choose non-profit organizations as their work places to earn their living. For those highly educated personnel, it is more difficult to resist the temptation of high-paying enterprises. Since China's resumption of the higher education on social work from 1988, by the end of 2015 , colleges and universities nationwide have cultivated social work graduates over 300,000 [18]. However, less than one-fourth of undergraduate major in social work will choose to be in social work, while less than one-fourth of on-job social workers can persist in doing social work without changing profession [19]. In this situation, non-profit organizations are beset by attracting highly-competent people.
Some managers in non-profit organizations generally have low academic qualifications and weak awareness of innovation. Just as said before, institutional innovation is quite important for emerging non-profit organizations. Therefore, the lack of qualified high-quality personnel is one of the problems needed to be solved urgently. Second, there is the lack of full-time managers with professional knowledge. Most non-profit organizations have a single staff composition, lack of professional manager majoring in financial planning and investment, restricting the development of non-profit organizations. Therefore, the issue of specialization of non-profit organizations deserves attention.

\subsection{Institutional Imperfection}

First, the organizational model of governance does not meet the needs of change. The organizational structure of commercial enterprises has a clear division of labor, market, public relations, finance and business functions. According to the development strategy of enterprises, each department takes its own duties, coordinating and working together to achieve the goals of the organization, which establishes a mature organizational operating system. On the contrary, the structure of most non-profit organizations is based on traditional charitable projects. With no commercial framework, the systems of financial management, equipment procurement and budget management are unsound. There is no specialized departmental support, resulting in the chaos of management. Although some large-scale organizations follow the example of overseas practices and devote themselves to fund-raising departments and operational departments that are responsible for the follow-up of the project, most of the non-profit organizations haven't upgraded organizational structure, but blindly imitate traditional operation [20].

\section{External Factors}

\subsection{Role of Government}

The development of modern public charity is more than just a matter of charitable organizations. All the forces of government departments, market departments, and the third sector should enter the field of social welfare and realize the cooperation [21]. The change of non-profit organizations needs the change of the government, which gives full play to each sector through cooperation and stimulates non-profit organizations to respond and participate. But the current governance idea lags behind the development trend of non-profit organizations. More emphasis is placed on regulation and control through the restrictions on the birth and development of charitable organizations by implementing the dual government system and limiting non-profit organizations within the scope of their authority [22].

What's relieved is that the government gradually highlights predicament and countermeasure, delegates power to non-profit organizations, and stimulates the vitality of organizations. However, such changes are always top-down. The government has long occupied the position of a monistic 
subject in state administration and has persisted in the administrative-led management. The government (the first sector) not only have some intersections with non-profit organizations (the third sector), but also largely lead the development of non-profit organizations [23]. The first is that the government mobilizes social works. Second, in order to survive, social organizations rely on the government to purchase social services. As a result, social work organizations have become dependent on the government. The paternalistic management of the government imposes restrictions on the autonomous development of organizations. In consequence, that's why the non-profit organizations have not made substantive progress in their reforms yet.

Thus, the relationship between non-profit organizations and the government is often seen as a relationship between the upper and lower levels. Non-profit organizations need to be anchored in the government and receive the supervision of the government. They are easily influenced by the administrative style of government and show the governmental color in their actions. This makes the change of non-profit organizations constrained, which apparently does not meet the requirements of the development of modern non-profit organizations. In order to solve the adverse effects of the regularities, managers tend to devote their resources to how to maintain the relationship with the government, precisely because the government has the right to formulate and enforce systems, policies and norms. Whether or not the organizations can gain institutional and policy support and inclination depends more on the relationship between the organizations and the government authorities [24].

\subsection{Regulations}

There is the most crucial obstacle encountered by non-profit organizations in their development. Without the guarantee of laws, non-profit organizations have danger of alienation and is not conducive to its healthy growth in society [25]. At present, the laws and regulations administered in non-profit organizations in our country are not normative. The development level of formal or informal systems among regions is highly uneven, causing geographical discrepancies in CEO management autonomy [26]. This is manifested in the following aspects. First of all, the higher the level of trust in developed regions, the more flexible organization which bring more autonomy for managers to engage in management. Second, more efficiency of governmental work in developed areas, higher transparency of policies, and simpler procedures all make the managers be less restrained and operate organizations more freely.

The lag of laws and policies has, in fact, constituted a major obstacle to the development in breadth and depth. On the one hand, the current legal and policy environment for non-profit organizations is by no means satisfactory to regulate and protect them. Up to now, there is no specific law in China to regulate the substantive contents of non-profit organizations. On the other hand, the relevant laws, regulations and policies already promulgated have not been implemented due to the scarce of specific and operational supporting policies.
Therefore, these have caused the current non-profit organizations still overly depend on the government.

\section{Conclusion}

These are the confusions and contradictions that we are now facing when analyzing the change of our non-profit organizations in China. To truly shape non-profit organizations a strong social force, the government should reduce its intervention in the market, the organizations should establish an effective operating system, and the society should give the organizations more support and generosity.

Some people say that China is the place where non-profit organizations are under strict regulation. However, as long as there is innovative thinking and actions, we may create many miracles. Only when non-profit organizations get rid of the shadow of the drawbacks, new thins could emerge from the old.

\section{References}

[1] Henry Minzberg, and Frances Westley (1992). Cycles of organizational change. Strategic Management Journal.

[2] Wang Jun (2015). Study on the path of private social work institution transform into the social enterprise. Anhui University.

[3] Pan Hanqing (2017). A preliminary study on the social circle of social workers in China. Capital University of Economics and Business.

[4] Feng Guan (2005). Research on organizational inertial change management. Liaoning Technical university.

[5] Finkelstein, S., and Hambrick (1990). Top-management-team tenure and organizational outcomes: the moderating role of managerial discretion. Administrative Science Quarterly.

[6] Nelson, R. R., and Winter, S. (1982). An evolutionary theory of economic change. Harvard University Press: Cambridge MA.

[7] Tian, Rong (2009). Development and transformation: A case study on social welfare nongovernmental organizations in Hong Kong. The University of Hong Kong.

[8] Garcia-Morales VJ, Florens-Montes. FJ, Verdu-Jover AJ. (2007). The effects of transformational leadership on organizational performance through knowledge and innovation. British Journal of Management.

[9] Zeng Jia, and Wang Na (2014). Analysis of problems faced by non-profit organizations in transformation of public welfare enterprises. Oriental Enterprise Culture.

[10] Sun Hua (2014). The development and reflection of private social work institutions_-Based on the investigation of Nanjing's development status. Journal of Nanjing Radio \& Television University.

[11] Cyert, R. M., and March, J. G. (1963). A behavioral theory of the firm, Prentice Hall. Englewood Cliffs, NJ.

[12] Cui Jinghong (2017). An analysis of the dilemma of charitable foundation in social governance and the countermeasures. Shandong University. 
[13] Lu Jinkang (2016). An analysis of the professional path of the modern transformation of China's social public welfare organizations. The Modern Occupation Education.

[14] Deng Guosheng (2001). A preliminary analysis of China's questionnaire survey. United Nations Centre for Regional Development, Institute of Science, Technology and Society, Tsinghua University, BJ.

[15] Jiang Yazhou, and Shi Congmei (2018). Feasibility analysis of the transformation of public welfare institutions to social enterprises - Based on the comparison of transformation experiences of three hospitals in Suzhou. Journal of Fujian Provincial Committee Party School of CPC.

[16] W. R. Scott (2001). Institutions and Organizations. California: Sage Publications. Inc.

[17] Zhang Yan, and Shi Bonian (2016). Education, providing professional support for the development of social work. China Social Work.
[18] Guo Xiaohui (2015). Research on the governance of charitable organizations commercialization in China. Shandong University.

[19] Zhou Hongyun (2016). Charity's institutional environment and transformation. China Social Organization.

[20] Wang Ming, and Sun Weilin (2011). Social organization management system: internal logic and development trend. Chinese Public Administration.

[21] Szelényi, I. (1983). Urban inequalities under state socialism. New York: Oxford University Press.

[22] Liu Zhimeng (2012). Studies on Chinese social enterprise in charity dilemma - The amity bakery as a case. Nanjing University of Science \& Technology.

[23] Zhang Sanbao, and Zhang Zhixue (2012). Regional system differences, CEO management sovereignty and corporate risk assumption-Evidence from 30 provincial technological industries. Management World. 